\title{
O Complexo de Salvador Ocidental: Pós-colonialismo e Feminismo no Oriente Médio
}

\author{
Laura Rodrigues Nóra ${ }^{1}$
}

\section{Resumo}

O presente trabalho trata da problemática oposição entre dois grupos representados como homogêneos e antagônicos. De um lado mulheres livres e emancipadas e de outro, mulheres oprimidas e submissas. Este trabalho tem por objetivo evidenciar como essa dicotomia se tornou um obstáculo para a percepção mais completa da realidade de muitas mulheres muçulmanas. Tal tema foi escolhido com o objetivo de contribuir para a desconstrução do famoso mito de homens brancos que salvam mulheres oprimidas. $\mathrm{O}$ estudo busca evidenciar como o poder da representação é uma ferramenta ideológica e, por isso disputado por muitos.Nessa lógica, também buscou-se mostrar que o Islã não pode ser considerado algo monolítico e que as visões generalizadoras sobre essa religião contribuem para posicionamentos preconceituosos. Assim, é um ponto importante para este trabalho a relação entre a religião e gênero e como foi possível o surgimento de um movimento feminista dentro do Islã. Este artigo ressalta a importância de repensar o entendimento de termos como emancipação e libertação a partir de contextos locais.

Palavras-chave:Feminismo - Pós colonialismo - Mulçumanas - Islã - Gênero

\begin{abstract}
The following study tackles the opposition between two groups represented as homogeneous and antagonistic. On the one hand, free and emancipated women, on the other hand, groups of oppressed and submissive women. This work aims to show how this dichotomy has become an obstacle to a more complete understanding of the reality of many Muslim women.This theme was chosen in order to contribute to the deconstruction of the famous myth of white men saving oppressed women. The study seeks to show that the power of representation can become an ideological tool and, therefore, it is disputed by many.In this logic, this work also sought to show that Islam cannot be regarded as something monolithic and that generalizing views on this religion contribute to biased positions. Thus, it is an important point for the study the relationship between religion and gender and how it was possible the emergence of a feminist movement within Islam. This article emphasizes the importance of rethinking the understanding of terms such as emancipation and liberation from local contexts.
\end{abstract}

Keywords: Feminism- Post colonialism- Muslim - Islam- Gender

\footnotetext{
1 Graduada em Relações Internacionais no Instituto de Estudos Estratégicos da Universidade Federal Fluminense. E-mail: laurarnora@gmail.com.
} 


\section{Introdução}

O presente trabalho tem por objetivo tentar compreender como ideias que pregam emancipação e liberdade podem ser convertidas em ferramentas de dominação e, principalmente, como o poder da representação é de fato uma ferramenta ideológica e, por isso sempre disputado no contexto internacional.

Esta pesquisa propõe-se a abordar dois principais problemas: a construção monolítica das mulheres não ocidentais e a usurpação do espaço de representação destas mulheres. É imprescindível nos questionarmos sobre como a mulher muçulmana é percebida no Ocidente. Essa percepção, resultado de múltiplas generalizações,foi reforçada por preconceitos e hostilidades que ganharam ainda mais força após os atentados de 11 de setembro.

Como afirma Saïd $(2007$, p.50), "todo aquele que escreve sobre o Oriente deve se localizar vis-à-vis ao Oriente". Assim, dentro dos diferentes "orientes" possíveis, o que vai interessar no esforço desta análise é o oriente islâmico.

No mundo atual, um governo costuma ser considerado "internacionalmente aceito" de acordo com sua capacidade de garantir os direitos civis, respeitar os direitos humanos e assegurar a igualdade entre os gêneros. Essas qualidades, normalmente, são diretamente relacionadas as organizações liberais ocidentais. Dessa forma, importantes atores do sistema internacional utilizaram o atentado ao World Trade Center para reforçar ainda mais essa visão, corroborando a ideia de que os países do mundo árabe, principalmente aqueles em que a religião islâmica predomina, são opositores dos direitos humanos e, em especial, do direito das mulheres.

Os termos"mulheres muçulmanas" ou "mulheres árabes" se tornaram uma categoria sociológica homogênea, caracterizada por dependências ou impotências em comum. Com frequência, essas mulheres são consideradas como pobres criaturas sem recursos, condenadas a uma obediência aos homens da família, ou como rostos sem identificação, vulneráveis e ignorantes, tampados pelo véu religioso. Ou seja, a imagem mais difundida é da mulher sem espaço na sociedade e sem dignidade para fazer suas próprias escolhas.

Essas visões preconceituosas e carregadas de estereótipos prejudicam uma melhor compreensão do mundo islâmico, muitos não compreendem que diversas mulheres no Oriente Médio não são passivas e submissas. Não podemos ignorar a existência de grupos feministas locais que se envolvem na política de resistência à desigualdade de gêneros. Muitas, de 
maneira organizada ou não, exercem pressão sobre o sistema, colocam questões importantes e demandam seus direitos como mulheres e cidadãs.

Nessa lógica, este trabalho tem a intenção de expor como a interpretação muito difundida de que o Islã pode ser considerado o responsávelpela desigualdade entre os gêneros no mundo mulçumano é incompleta. Em contrapartida, pretende-se evidenciar como, em alguns casos, as ideias libertárias que dão base para intervenção de agentes internacionais nesses países podem ser consideradas como uma ferramenta de movimentos colonialistas.

Pretende-se desconstruir a imagem popular de mulheres vitimadas pelo Islã e sem capacidade de se organizarem localmente. Este artigo não busca realizar mais um estudo que possa ser considerado orientalista, com o objetivo de representar ou falar por algum grupo específico. Este trabalho é na verdade a tentativa de uma produção não repressiva e não manipuladora, busca-se desconstruir o "Outro" apenas como um objeto do conhecimento.

\section{0 poder da representação}

Em 2011 os Estados Unidos da América utilizaram a imagem de mulheres impossibilitadas de frequentar escolas para suscitar apoio nacional e internacional para intervir no Oriente Médio e promover a guerra contra o terrorismo. Nesse momento, foi evidenciada a ligação direta entre a promoção dos direitos das mulheres árabes e a luta contra o terrorismo, com o objetivo de justificar os bombardeios americanos no Iraque e no Afeganistão.

A igualdade de gênero é um tema central no debate mais amplo que questiona se o Islã se encaixaria ou não nas regras seculares europeias, nos parâmetros de democracia e direitos humanos. Gayatri Spivak (2010) denunciou que algumas das críticas mais radicais produzidas pelo Ocidente hoje, são o resultado de um desejo interessado em manter o Ocidente como sujeito principal.

O véu islâmico, seja o hijab, o niqab ou a burca, são representados atualmente como símbolos de opressão. Muitas vezes, as ideologias já consolidadas partem de premissas que restringem a assimilação entre as crenças religiosas islâmicas e os Direitos Humanos.Contudo, o debate sobre os direitos das mulheres muçulmanas deveria ser precedido pelo questionamento sobre a universalidade dos direitos humanos.

Nesse sentido, guerras são justificadas através da lógica de identidades opostas e contrastantes. Historicamente, foi assim que o orientalismo combinado a visões preconceituosas e machistas transformou o feminismo ocidental em uma ferramenta de 
opressão. Spivak mostra como as mulheres "nativas" podem ser usadas para justificar projetos coloniais, como missões civilizatórias. Ela notadamente descreveu a intervenção britânica na Índia como "homens brancos salvando mulheres pardas de homens pardos”(1988, p. 297).

Ao mesmo tempo, muitos dos esforços anticoloniais e em favor do nacionalismo, também utilizaram a imagem da mulher para simbolizar a nação e se empenharam em articular um papel significativo para as mulheres nos processos de construção nacional e de descolonização. Sinha (1995, p.45) nota que, na Índia, “a estratégia anglo-indiana de usar a subordinação das mulheres na Índia como um meio conveniente de conter os anseios de igualdade política dos indianos transfigurou a 'questão da mulher' em um campo de batalha nos direitos políticos dos indianos".

Assim, a da mulher árabe é quase sempre representada como vítima de um véu que apaga todos os traços de identidade, mulheres transformadas em uma massa uniforme, tristes e submissas, vestidas de preto da cabeça aos pés e submissas aos homens da sua sociedade. Estes homens mulçumanos, inseridos na mesma lógica, são facilmente classificados como um inimigo desconhecido, principalmente, em épocas de crise e insegurança.

Segundo Pepicelli (2008, p.92), "planos de cooperação internacional, da mesma forma que intervenções armadas, se justificam como atos de defesa dos Direitos Humanos, e dos direitos das mulheres, particularmente". Assim, tanto a Guerra do Iraque quanto a Guerra do Afeganistão rapidamente ganharam um caráter de "lutas a favor dos direitos humanos e das mulheres".

Fica evidente que no mundo Ocidental é comum pensarmos nas mulheres muçulmanas e árabes como um grupo monolítico, visto que com frequência o termo que se refere a etnia (árabe) é confundido com o que identifica a religião (mulçumano). Assim, faz-se necessário uma análise menos superficial sobre a religião islâmica e seus significados para que possamos entender as lógicas locais desse "oriente islâmico".

\section{Seriao Islã contrário ao feminismo?}

O islã surgiu no século VII, na região da Península Arábica, baseado em premissas proféticas, quando Mohammed recebeu mensagens divinas, que posteriormente foram condensadas em um livro sagrado, o Corão. O aglomerado dos códigos estabelecidos é denominado de Sharia, reunindo as leis postas no livro como jurisprudência para todos os muçulmanos baseada em ações de Maomé que foram documentadas (BRANCOLI, 2015). É 
esse conjunto de normas que irá, muitas vezes, servir como arcabouço máximo da política de alguns países - até mesmo servindo como base constitucional (Idem). Já a comunidade formada pelos muçulmanos que seguem esse aparato jurídico e religioso seria conhecida como umma, comunidade imaginada que representa o conglomerado político mais importante na lógica islâmica.

Pinto (2010) aponta que Mohammed combinou elementos de liderança política, religiosa e militar. Esse fato é utilizado muitas vezes, como justificativa para que questões religiosas transbordem para o mundo das relações de poder dentro de sociedades de maioria muçulmana. Brancoli (2015, p.152) afirma que "o Islã Político, dentro dessa lógica, pode ser definido como "uma forma de instrumentalização desta religião por indivíduos, grupos e organizações que possuem objetivos políticos”.

A atividade política em nome do Islã contemporâneo é derivada do encontro com forças ocidentais, a partir do século XVIII, encontros inseridos em um cenário de dominação europeia colonial. Esse cenário, na interpretação islâmica, representava a inversão de uma realidade divina, em que a comunidade muçulmana deveria estar na vanguarda das capacidades globais (BROWN, 2000).

O Islã político, dessa forma, forneceu a justificativa para diversas disputas contra potências imperialistas. Nesses casos, a religião se apresenta como uma ideologia política ao invés de uma filosofia teológica. Dessa forma, no decorrer da história, os países do Oriente Médio e, principalmente, os de maioria muçulmana, são vistos pelo Ocidente como uma ameaça. Saïd (2012) explica que o mundo árabe costuma ser representado pelo Ocidente como uma região longe da civilização. Essa maneira específica de abordagem do Oriente orientalismo - foi desenvolvida pelo Ocidente com o objetivo de dominar e ter autoridade sobre a região.

Essa instrumentalização é facilmente percebida ao observarmos os estereótipos da mulher não ocidental, utilizada como mais uma ferramenta para reforçar a oposição entre Islã e Ocidente. O Feminismo no Islã sempre foi presumido como inexistente pelo Ocidente. Do ponto de vista orientalista, o mundo árabe é incapaz de produzir uma ideologia que busca a igualdade entre os gêneros, a religião islâmica não permitiria. Assim, a comoção gerada em torno do tema "mulheres muçulmanas oprimidas" foi e é utilizado para justificar incursões coloniais e neocoloniais em sociedades de maioria muçulmana. (BADRAN, 2002).

A socióloga Marnia Lazreg escreveu sobre como o controle colonial das vozes femininas se deu ao longo da história. Ao comentar sobre o caso Argeliano, a autora 
evidenciou como membros do exército francês trouxeram mulheres das aldeias do país para a capital, Argel. Os francesesrealizaram uma cerimônia de "retirada do véu" das argelianas por mulheres francesas, com o intuito de evidenciar um apoio das mulheres locais a ocupação francesa no país. De acordo com Marnia (1994), o evento do dia 16 de maio de 1958 (apenas quatro anos antes da Argélia conquistar sua independência da França após 130 anos de controle francês) é talvez o exemplo mais claro de apropriação colonial e silenciamento das vozes femininas.

Segundo Lazreg (1994):

On that day a demonstration was organized by rebellious French generals in Algiers to show their determination to keep Algeria French. To give the government of France evidence that Algerians were in agreement with them, the generals had a few thousand native men bused in from nearby villages, along with a few women who were solemnly unveiled by French women. ${ }^{2}$

As mulheres francesas neste momento estavam prestando um serviço ao patriarcado colonialista da França. O evento coreografado na época denota uma constante no processo colonial: a instrumentalização das mulheres para se atingir objetivos que não se relacionam com a igualdade de gênero ou a luta pelos direitos das mulheres.

Assim, essas duas construções ideológicas - Oriente Islâmico versus Ocidente laico não levam em consideração a construção sócio cultural de crenças e sua metamorfose através da história (ARKOUN, 2006). O Corão oferece normas e valores religiosos através de paradigmas e metáforas (PINTO, 2010) que podem ser interpretados de diferentes maneiras, assim como acontece com a Bíblia. Logo, o efeito normativo desses elementos textuais varia em cada sociedade muçulmana.

\section{Islã e gênero}

A visão generalizadora do papel do Islã na determinação do status da mulher nos países de maioria muçulmana parte muitas vezes de interpretações imprecisas sobre essas sociedades (DERICHS, 2010). A concepção muito difundida de que o Islã pode ser considerado o responsável pela desigualdade entre os gêneros é enviesada. O Islã é na verdade um sistema de práticas e crenças repleto de diversas questões que são constantemente

\footnotetext{
${ }^{2}$ Tradução do Autor: "Nesse dia uma demonstração foi organizada pelos Generais franceses rebeldes em Argel para mostrar a sua determinação em manter a Argélia francesa. Para dar uma evidência ao governo francês de que os argelinos concordavam com eles, os generais trouxeram de pequenas aldeias próximas alguns milhares de homens nativos, juntamente com algumas mulheres que foram solenemente livradas do véu por mulheres francesas."
} 
repensadas e atualizadascom frequência, assumindo novos significados diante de momentos históricos diversos.

Nessa lógica, Asma Barlas (2008, p.17) afirma que "Muçulmanos interpretam o Islã de maneira patriarcal devido a maneira como eles leem o Corão, quem lê e o contexto em que se lê os textos sagrados. Em outras palavras, os textos são sempre lidos a partir de um ponto ideológico específico e nós precisamos estar atentos a esse ponto de partida para tentar compreender a leitura de escrituras". Utilizando ferramentas da ciência religiosa islâmica junto com outras da ciência social moderna, especialistas conseguiram demonstrar que o patriarcado na estrutura familiar e na sociedade em geral não é uma determinação do Islã.

Atualmente, existem especialistas religiosos que desafiam as formas como os textos sagrados são apresentados e interpretados. Essa nova tendência faz oposição a ideia de que os textos corânicos são exclusivamente prescritivos ou leis sem conexão alguma com o contexto em que foram desenvolvidas (RHOUNI, 2008). Fatima Mersnissi (1987), por exemplo, uma das primeiras mulheres a publicar um livro sobre esse assunto, introduziu a ideia de que o Corão surgiu primeiramente na forma oral fazendo com que os discursos do Profeta ficassem expostos às reações dos primeiros atores e as preocupações particulares da sociedade árabe da época.

Podemos identificar o Islã como um instrumento intelectual de formação e não como um determinante de comportamentos, a religião nesse caso é uma variável utilizada para justificar determinadas práticas políticas e sociais. Nessa lógica, o Islã pode-se tornar uma ferramenta do patriarcado e determinadas premissas da religião são selecionadas e reinterpretadas para auxiliar na construção de uma sociedade desigual. De acordo com Honarbin-Holliday (2008, p.4, tradução livre), "limitações e restrições sobre as mulheres não são, necessariamente, demandadas ou projetadas pelo pensamento islâmico. Ao contrário, elas são construídas ao longo de séculos de patriarcado em nome do Islã. O Islã defende a aprendizagem e voz para homens e mulheres".

Algumas especialistas no assunto são até mesmo mais radicais. Zara Faris, uma pesquisadora paquistanesa, publicou um artigo comparando a situação das mulheres durante o Califado Otomano e das mulheres ocidentais no mesmo período. Para Zara (2013), a ausência do Islã foi o que levou as mulheres ocidentais a desenvolverem o feminismo, como uma solução para as desigualdades de gênero enfrentadas na sociedade ocidental pós-iluminismo. Segundo Faris, as mulheres que viviam no Califado Otomano gozavam de maior liberdade e proteção do que as mulheres ocidentais e exatamente por isso não necessitavam de feminismo 
para obter seus direitos. Já as mulheres do Califado apenas precisavam da implementação completa do seu sistema de crenças, o Islã.

Embora a religião promova importantes influências na vida das mulheres, essas influências devem ser entendidas dentro dos contextos históricos, sócio-políticos e econômicos mais amplos. Assim como acontece nos países do Ocidente, as duas regiões constituem sistemas de controle majoritariamente patriarcal, o equívoco está em fazer comparações que sustentam pretensões de superioridade de uma região sob a outra.

\section{Feminismo no Islã}

Historicamente, mulheres muçulmanas desenvolveram dois principais paradigmas feministas, o feminismo secular e o feminismo islâmico. O feminismo secular surgiu primeiramente no território dos Estados nações emergentes na África e na Ásia no final do século XIX e na primeira metade do século XX (BADRAN, 2002). Esse desenvolvimento acompanhou os processos de modernização, luta nacionalista anticolonial, declínio de dinastias e a construção de Estados independentes na região. $\mathrm{O}$ feminismo secular significava um modelo de feminismo localizado dentro do contexto do Estado nação secular composto por cidadãos iguais independente de religião, um Estado protetor da religiosidade, mas não oficialmente organizado ao redor dela. Já o feminismo islâmico surge na cena global como um novo discurso e forma de interpretar o Islã e gênero, baseado na investigação intelectual independente dos textos religiosos (Idem). O cenário islâmico/religioso desse novo feminismo não implica na necessidade de secularização, Badran (2008) o defini como "discurso de igualdade de gênero que deriva seu mandato do Corão e busca direitos e justiça para todos os seres humanos na totalidade das esferas públicas e privadas".

Esses dois paradigmas abordam a igualdade de gênero de forma diferente. O feminismo secular insiste na igualdade de acesso à esfera pública nos domínios da educação secular e trabalho, direitos políticos, revisão da lei da família e na necessidade de que o homem honre suas responsabilidades com a família (BADRAN, 2002). Em contraste, o feminismo islâmico vai além da construção patriarcal da família ao afirmar que esse modelo não é compatível aos princípios corânicos de igualdade humana e justiça de gênero.

O feminismo islâmico promove a igualdade através de uma esfera pública- privada mais fluida. Este conectou não só o público e o privado, mas também elucidou a necessidade da conexão entre igualdade de gênero e justiça social. $\mathrm{O}$ feminismo islâmico é libertador na 
medida em que é inclusivo e baseado em noções de justiça que ultrapassam as barreiras das dicotomias e divisões improdutivas.

No cerne do feminismo islâmico está a recuperação pelos mulçumanos da prática chamada ijtihad - interpretação crítica e independente dos textos religiosos. Para MirHosseini (2006), o feminismo islâmico está de fato "mostrando como as construções desiguais contradizem a essência da justiça divina que é revelado pelo Alcorão e como os textos sagrados do Islã foram prejudicados pelas ideologias dos seus interpretes".

Apesar disso, muitas mulheres produtoras do discurso islâmico sensível aos direitos das mulheres não consideram seu trabalho como parte de um "projeto feminista". Algumas resistem a essa classificação, pois acreditam que o termo "feminismo" é cumplice da representação do Islã como sinônimo opressor (BARLAS, 2008). O feminismo islâmico ainda é muito fluido e o debate sobre exatamente o que é e quem pertence a classificação ainda está aberto. Consequentemente, esse movimento possibilita o surgimento de diferentes pontos de vista, e é comum que muitas ainda não se reconheçam como feministas islâmicas (PEPICELLI, 2008). Sobre essa questão, Mir-Hosseini (2006) afirma que "é difícil e talvez fútil colocar vozes feministas emergentes do Islã em categorias tão puras para tentar gerar uma definição que reflete a diversidade das posições dentro do feminismo islâmico. Assim como outras feministas, suas posições são locais, diversas e múltiplas". Apesar de nem sempre concordarem no que constitui justiça ou igualdade, todas as estudiosas do assunto buscam justiça de gênero e igualdade para as mulheres.

Independente da classificação ou "etiqueta" que cada intelectual do tema recebe, a contribuição mais revolucionária das mulheres que pensam o feminismo dentro do Islã é o fato de existirem mulheres desafiando autoridades e abrindo espaço para diálogo entre diferentes personalidades e identidades.

Assim, percebe-se que a imagem que é articulada sobre o Islã e as mulheres muçulmanas é com muita frequência carregada de concepções preconceituosas e que nem sempre exprimem a realidade. Pode-se identificar que discursos fundamentalistas e machistas, proferidos com o intuito de reduzir o papel da mulher na sociedade, podem encontrar um denominador comum, independente da religião ou da forma de organização política. É possível concluir também que o Islã e o feminismo não são categorias completamente opostas e excludentes, mas que a construção antagônica entre a mulher ocidental totalmente livre versus a mulher muçulmana oprimida e submissa é muito problemática. 


\section{Vestimenta e liberdade}

O véu islâmico que é tão debatido e visto como símbolo de submissão no Ocidente é para muitas mulheres um símbolo externo de crença espiritual. Não é uma bandeira política para o Estado islâmico, não é um sinal de submissão das mulheres aos homens, não é um teste decisivo para a religiosidade, o véu é uma oportunidade de exercer sua liberdade de escolha.

Abu- Lughod (TIME, 2013) afirma que:

30 years ago the anthropologist Hanna Papanek described the burqa as "portable seclusion" and noted that many women saw it as a liberating invention because it enabled them to move out of segregated living spaces while still observing the requirements of separating and protecting women from unrelated men. ${ }^{3}$

Foi por isso que o mundo ficou tão surpreso quando muitas mulheres no Afeganistão não tiraram o véu após a "libertação" do país(TIME, 2013). Com muita frequência, confundese o véu com a falta de agência ou impossibilidade de organização.

As vulnerabilidades das mulheres no Oriente Médio e no mundo, incluindo o Ocidente, estão ligadas principalmente as antigas hierarquias de gênero em diferentes cenários. Políticas de gênero, restrições econômicas e educacionais acumularam percepções socioculturais e condições desiguais. A interpretação religiosa é apenas um elo na cadeia das causas que colocam as mulheres em perigo.

Pessoas no mundo inteiro, ocidentais e orientais, utilizam vestimentas compatíveis com seus padrões sociais, crenças religiosas e ideais morais. Ao partimos do princípio de que a mulher ocidental está inserida em um mundo de livre escolha em relação as roupas, esquecemos de analisar nossos próprios códigos de vestimenta e até mesmo a tirania da moda que constrange tantas mulheres.

Ao representarmos o véu muçulmano como um símbolo de opressão, reduzimos a liberdade do grande número de mulheresque escolheram cobrir suas cabeças e/ou corpos. Outro fator importante é que mulheres muçulmanas são, com maior frequência, vítimas de casos de preconceito religioso. A maioria dos muçulmanos atacados fisicamente, perseguidos e intimidados por causa da sua fé são mulheres que utilizam o véu. Assim, discursos que estimulam essa oposição entre as formas de se vestir prejudicam, primeiramente, as mulheres.

\footnotetext{
${ }^{3}$ Tradução do Autor: "Há 30 anos, a antropologista Hanna Papanek descreveu a burqa como "reclusão portátil" e notou que muitas mulheres viam essa vestimenta como uma invenção libertadora, pois permitia que elas deixassem espaços segregados e ainda continuassem de acordo com as regras de separação e protegia as mulheres de homens desconhecidos".
} 


\section{Conclusão}

Como foi observado ao longo desse trabalho, podemos verificar a existência históricada problemática em que estrangeiros repletos de boas intenções utilizaram noções deturpadas para salvar "outras mulheres". Esse processo contribuiu em larga escala para o superestimado mito dos heróis brancos que salvam mulheres orientais da opressão, sem levar em consideração a sua cultura, crenças ou opinião.

Esta reflexão não buscou provar a inexistência de mulheres oprimidas dentro do mundo muçulmano, mas sim evidenciar como essa visão é na verdade incompleta. É de conhecimento geral a existência de radicais muçulmanos que pregam o confinamento feminino a esfera privada, delegando às mulheres apenas os papéis de esposa ou mãe.

O fato é que a questão da luta pela igualdade pode ser entendida como universal, visto que a opressão das mulheresé uma realidade tanto no Oriente quanto no Ocidente. Contudo, como um campo global e amplo, essa desigualdade varia em diferentes camadas de complexidade.

De acordo com a estatística das Nações Unidas (UN WOMEN, 2016), uma em cada três mulheres já enfrentaram ou irão enfrentar violência física ou sexual durante as suas vidas. Mulheres são afetadas desproporcionalmente pela pobreza, acesso à educação, enfrentam pagamentos desiguais, instabilidade e exploração.

Assim, se repensarmos o entendimento de termos como emancipação e libertação a partir de contextos locais seremos capazes de entender como mulheres, baseadas em suas experiências pessoais e escrituras sagradas, são capazes de constituir sua própria autonomia e independência.Ao abrirmos as portas para uma nova representação do "outro", uma imagem desenhada pelos próprios sujeitos, permite-se que essa "outra" mulher muçulmana exista e seja percebida e reconhecida pelo Ocidente.

\section{Referências bibliográficas}

ARKOUN, Mohammed. Humanisme et Islam: Combats et propositions. Paris: Vrin, 2006.

BADRAN, Margot. Islamic feminism: identities and positionalities.Engaging Islamic Feminism.In Islamic Feminism: Current Perspectives, Tapri Occasional Papers, Tampere, Tampere Peace Research Institute, 2008, pp. 25-36. 
BADRAN, Margot. Foreign Bodies. Engendering Them and Us.In Saunders, Rebecca (ed.) The Concept of Foreign.An Interdisciplinary Dialogue. Lanham, MD: Lexington Books, 2002.

BARLAS, Asma. Islamic feminism: identities and positionalities.Engaging Islamic Feminism: Provincializing Feminism as a Master Narrative, in Islamic Feminism: Current Perspectives, Tapri Occasional Papers, Tampere, Tampere Peace Research Institute, 2008, pp. $15-23$.

BRANCOLI, Fernando. Islã Político, Direitos Humanos e Democracia: rearticulações e possibilidades. Monções: Revista de Relações Internacionais da UFGD , v. 3, p. 149-168, 2015.

BROWN, L.Carl. (2000). ReligionandState:TheMuslimApproachtoPolitics. 3.ed. Nova York: Columbia University Press.

DERICHS, Claudia. Diversity and Political Participation in the arab world. Diversity and Female Political Participation: Views on and from the Arab World, Heinrich Böll Foundation, V. 21, 2010.

FARIS, Zara. Ottoman Women During the Advent of Western Feminism, 2013.Disponível em: $<$ https://thedebateinitiative.com/2013/08/03/ottoman-women-during-theadvent-of-western-feminism/> . Acessoemmaio 2016.

HONARBIN-HOLLIDAY, Mehri. Becoming visible in Iran : Women in Contemporary Iranian Society. Londres: Tauris Academic Studies, 2008.

LAZREG, Marnia. The Eloquence of Silence: Algerian Women in Question, New York: Routledge, 1994.

MIR-HOSSEINI, Ziba.Muslim Women's Quest for Equality: Between Islamic Law and Feminism.Critical Inquiry 32(4), 629-645, 2006.

MERNISSI, Fatima. Le Harem politique: leProphete et lesfemmes. Paris: Albin Michel, 1987.

PEPICELLI, Renata. Islamic feminism: identities and positionalities. Why keep asking me about my identity? Thoughts of a non Muslim, in Islamic Feminism: Current Perspectives, Tapri Occasional Papers, Tampere, Tampere Peace Research Institute, 2008, pp. 91-102.

PINTO, Paulo Gabriel. Islã : religião e civilização: uma abordagem antropológica. Rio de Janeiro: Santuário, 2010.

RHOUNI, Raja. Islamicfeminism: identitiesandpositionalities.Rethinking "Islamic Feminist Hermeneutics:" The Case of Fatima Mernissi, in Islamic Feminism: Current Perspectives, Tapri Occasional Papers, Tampere, Tampere Peace Research Institute, 2008, pp. 103-115.

SAID, Edward W. Orientalismo - O Oriente como invenção do Ocidente.São Paulo: Companhia das Letras, 2007. 
SINHA, Mrinalini. Colonial Masculinity: The "Manly Englishman" and the "Effeminate Bengali" in the Late Nineteenth Century. Manchester: Manchester UniversityPress, 1995.

SPIVAK, Gayatri. Pode o Subalterno falar? Belo Horizonte: Editora UFMG, 2010. Disponível em: $<$ https://joaocamillopenna.files.wordpress.com/2013/10/spivak-pode-osubalterno-falar.pdf $>$ Acessado em junho de 2016.

TIME. Do Muslim Women Need Saving?, 2013. Disponível

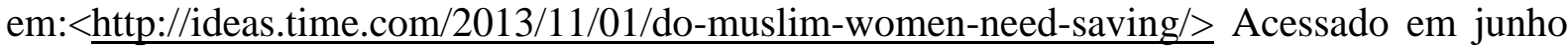
de 2016.

UN WOMEN. Violence Against Women, 2015.Disponível em: $<$ http://www.unwomen.org/en/digital-library/multimedia/2015/11/infographic-violenceagainst-women> Acessado em julho de 2016. 